\title{
Effect of erythropoietin on the incidence of acute kidney injury following complex valvular heart surgery: a double blind, randomized clinical trial of efficacy and safety
}

Ji-Ho Kim ${ }^{1}$, Jae-Kwang Shim², Jong-Wook Song ${ }^{2}$, Young Song ${ }^{2}$, Hye-Bin Kim² and Young-Lan Kwak ${ }^{3 *}$

\begin{abstract}
Introduction: Recombinant human erythropoietin (EPO) is known to provide organ protection against ischemia-reperfusion injury through its pleiotropic properties. The aim of this single-site, randomized, case-controlled, and double-blind study was to investigate the effect of pre-emptive EPO administration on the incidence of postoperative acute kidney injury (AKI) in patients with risk factors for AKI undergoing complex valvular heart surgery.

Methods: We studied ninety-eight patients with preoperative risk factors for AKI. The patients were randomly allocated to either the EPO group $(n=49)$ or the control group $(n=49)$. The EPO group received $300 \mathrm{IU} / \mathrm{kg}$ of EPO intravenously after anesthetic induction. The control group received an equivalent volume of normal saline. AKI was defined as an increase in serum creatinine $>0.3 \mathrm{mg} / \mathrm{dl}$ or $>50 \%$ from baseline. Biomarkers of renal injury were serially measured until five days postoperatively.

Results: Patient characteristics and operative data, including the duration of cardiopulmonary bypass, were similar between the two groups. Incidence of postoperative AKI $(32.7 \%$ versus $34.7 \%, P=0.831)$ and biomarkers of renal injury including cystatin $C$ and neutrophil gelatinase-associated lipocalin showed no significant differences between the groups. The postoperative increase in interleukin- 6 and myeloperoxidase was similar between the groups. None of the patients developed adverse complications related to EPO administration, including thromboembolic events, throughout the study period.
\end{abstract}

Conclusions: Intravenous administration of $300 \mathrm{IU} / \mathrm{kg}$ of EPO did not provide renal protection in patients who are at increased risk of developing AKI after undergoing complex valvular heart surgery.

Trial registration: Clinical Trial.gov, NCT01758861

\section{Introduction}

Despite advances in the understanding of its pathophysiology, acute kidney injury (AKI) continues to be a serious complication following cardiac surgery [1]. AKI is an independent predictor of both in-hospital and long-term mortality in cardiac surgical patients [2]. Of note, even a minor increase in serum creatinine $(\mathrm{sCr})$ level is associated with increased risk of morbidity and mortality, not to mention

\footnotetext{
* Correspondence: ylkwak@yuhs.ac

${ }^{3}$ Biomedical Science Institute, Department of Anesthesiology and Pain Medicine, Anesthesia and Pain Research Institute, Yonsei University Health System, 250 Seongsanno, Sedaemun-gu, Seoul 120-752, South Korea
} Full list of author information is available at the end of the article that the most severe disease spectrum of AKI requires dialysis $[3,4]$.

Patient-related factors and cardiopulmonary bypass (CPB) are considered major risk factors for AKI [5]. CPB is associated with inevitable alterations contributing to the development of AKI, such as ischemia-reperfusion injury, systemic inflammatory response, hemodilution, and embolism [6]. Indeed, the reported incidence of AKI after cardiac surgeries that required prolonged durations of CPB reaches $40 \%$ to $50 \%$, depending on the chosen definition [7]. Considering its high prevalence and clear association with poor prognosis, the development of renal protective strategies is important, especially in patients

\section{Ciomed Central}


with known risk factors for AKI undergoing surgeries requiring prolonged durations of $\mathrm{CPB}$.

Erythropoietin (EPO) is a natural hormone produced mainly in the kidney that regulates hematopoiesis. Apart from its hematopoietic effect, recent literature supports a protective role against ischemia-reperfusion injury through its anti-oxidative, anti-inflammatory and anti-apoptotic effects [8-10]. Indeed, EPO has been shown to decrease myocardial and renal damage after hypoxic insult in numerous experimental studies; however, conflicting results have been reported in clinical studies [11-13]. Despite its extensive experimental background, evidence is lacking regarding EPO's renal protective effect in cardiac surgical patients who are at increased risk of developing AKI.

The aim of this single-site, randomized, controlled and double-blind study is to validate whether a pre-emptive single bolus of recombinant human EPO mitigates the occurrence of AKI following complex valvular heart surgery in patients with preoperative risk factors for AKI.

\section{Materials and methods Patients}

After approval by the institutional review board of the Severance Hospital, Yonsei University Health System, Seoul, Korea, and procurement of informed consent, we studied ninety-eight patients with preoperative risk factors for AKI who were scheduled for complex valvular heart operations. This single-site trial was conducted at Yonsei University Health System, Seoul, Korea (ClinicalTrials.gov NCT0178861). Enrollment criteria for high risk of AKI included more than two of the following: female, chronic obstructive pulmonary disease, preoperative creatinine $>1.2 \mathrm{mg} / \mathrm{dl}$, New York Heart Association functional class IV, left ventricle ejection fraction $<35 \%$, diabetes mellitus (DM), age $>65$ years or peripheral vascular disease [5]. Complex valvular heart operations were defined as double-valve surgery, combined valve and coronary artery bypass grafting procedures, Bentall operations, combined mitral valve surgery and tricuspid annuloplasty or repeat operations. Patients with pre-existing uncontrolled hypertension (diastolic blood pressure $>100 \mathrm{mmHg}$ ), immunosuppression, history of thromboembolism, malignant disease, seizure, liver dysfunction, end-stage renal disease requiring renal replacement therapy and drug or alcohol abuse were excluded.

\section{Treatment}

Patients were randomly allocated to either the EPO or control group in a 1:1 ratio according to simple randomization using a computer-generated random code. Patients in the EPO group received $300 \mathrm{IU} / \mathrm{kg}$ of human recombinant EPO-alpha (Epocain; CJ Pharma, Seoul, Korea) intravenously after anesthetic induction. Patients in the control group received an equal volume of normal saline at the same time point. Medications were prepared by a nurse who knew the patient's group assignment but was not involved in the study.

\section{Clinical evaluations}

The primary endpoint of interest was incidence of AKI, which was diagnosed according to the Acute Kidney Injury Network (AKIN) criteria (absolute increase in the $\mathrm{sCr}$ concentration $\geq 0.3 \mathrm{mg} / \mathrm{dL}$ from baseline or $\geq 50 \%$ increase in the $\mathrm{sCr}$ concentration within 48 hours after operation) [14].

The secondary outcomes assessed in this study were biomarkers of renal injury including $\mathrm{sCr}$, cystatin $\mathrm{C}$, and estimated glomerular filtration rate (eGFR) which were recorded 24 hours before operation, upon arrival at the ICU, and on postoperative days (POD) $1,2,3$, and 5 . Additionally, changes in serum IL-6, myeloperoxidase (MPO) and neutrophil gelatinase-associated lipocalin (NGAL) levels in 18 randomly selected patients from each group were measured after anesthetic induction, at 1 and 6 hours after removal of the aortic cross clamp (ACC), and 24 hours after operation. Quantikine human IL-6 and Quantikine human MPO (R\&D System Inc., Minneapolis, MN, USA) were used to measure IL-6 and MPO. NGAL was measured by Human Lipocalin-2/ NGAL Immunoassay (R\&D System Inc., Minneapolis, MN, USA).

Preoperative variables included demographic data, type of operation and co-morbid conditions such as DM, hypertension, chronic kidney disease, cerebrovascular accidents, congestive heart failure, medications and EuroSCORE.

Intraoperative variables included operation time, duration of ACC and CPB, fluid balance, and packed erythrocyte transfusion requirement. The amount of ultrafiltration during $\mathrm{CPB}$ and the amount of salvaged blood by a cell salvage device during the operation were also recorded.

Postoperative variables included packed erythrocyte transfusion requirement, fluid balance and bleeding measured by chest tube drainage during the 24 hours after the operation. Hematocrit was measured preoperatively and on POD $0,1,2,3$, and 5 . Other postoperative variables were length of ICU and hospital stay, prolonged mechanical ventilator care ( $>48$ hours), inotrope use, re-intubation, reoperation, atrial fibrillation, stroke and in-hospital mortality. Possible complications associated with EPO treatment, such as hypertension, headache, tachycardia, nausea, vomiting, diarrhea and thromboembolism, were also assessed during the study period.

\section{Perioperative management}

All patients received standard anesthetic care. Standard monitoring devices included a pulmonary artery catheter and transesophageal echocardiography. Mechanical ventilation was controlled to maintain normocarbia with 
a tidal volume of $8 \mathrm{~mL} / \mathrm{kg}$ and respiratory rate of 8 to 14 breaths/minute.

All patients received standard surgical and $\mathrm{CPB}$ management with ultrafiltration. $\mathrm{CPB}$ was instituted with a membrane oxygenator primed with $1.6 \mathrm{~L}$ of priming solution. Non-pulsatile pump flow was maintained at a rate of 2.0 to $2.4 \mathrm{~L} / \mathrm{min} / \mathrm{m}^{2}$. During the intraoperative period, including $\mathrm{CPB}$, mean arterial pressure was maintained at 50 to $80 \mathrm{mmHg}$ with norepinephrine or sodium nitroprusside.

During the perioperative period, fluid balance was maintained using Voluven ${ }^{\circ}$ (Fresenius Kabi, Graz, Austria) and Plasma solution A 1000 inj $^{\circ}$ (CJ Pharma, Seoul, Korea) to maintain normovolemic status. Total volume of intraoperative Voluven ${ }^{\bullet}$ was limited to less than $20 \mathrm{ml} / \mathrm{kg}$ and/or $1,000 \mathrm{ml}$. The threshold for transfusion of packed erythrocytes was hematocrit $<20 \%$ during CPB or $<25 \%$ after CPB. After heparin was antagonized with protamine, blood from the CPB circuit was salvaged using a cell salvage device and re-transfused into all patients.

For postoperative hemodynamic management, norepinephrine or nicardipine was used to maintain mean arterial pressure between 65 to $90 \mathrm{mmHg}$. As an inotrope, milrinone was used if the left ventricular ejection fraction was lower than $30 \%$ or in cases of right ventricular dysfunction and/or pulmonary hypertension. Diuretics were used when hourly urine output was less than $0.5 \mathrm{ml} / \mathrm{kg}$. Blood glucose levels were targeted between 100 and $250 \mathrm{mg} / \mathrm{dL}$ with insulin throughout the study period.

\section{Statistical analysis}

Data were analyzed with SPSS version 19.0 statistical software (SPSS INC, an IBM Company, Chicago, IL, USA) and SAS version 9.2 (SAS Institute Inc., Cary, NC, USA). Results are expressed as mean \pm SD, median (interquartile ranges (25th to 75th)) or number of patients (percentages). Continuous variables were compared using independent Student's $t$-test or Mann-Whitney $U$ test, and dichotomous variables were compared using chi-square or Fisher's exact test as appropriate. The Shapiro-Wilk test for normality was performed. NGAL and inflammatory cytokine levels were log-transformed. Repeatedly measured variables, such as creatinine, cystatin C, eGFR, log NGAL, log IL-6 and log MPO were analyzed using a linear mixed model as a group, time and group-by-time as fixed effects. Type I error was corrected by the Bonferroni method. All statistical tests were two-tailed. $P$-value less than 0.05 was considered statistically significant. In a previous institutional study, the incidence of AKI following valvular heart surgery in anemic patients was 54\%, [13] and EPO reduced the incidence of AKI more than $50 \%$ in two previous clinical studies $[11,13]$. Therefore, we determined that 49 patients were required in each group to detect a $50 \%$ reduction in the incidence of AKI between the groups to obtain a power of $80 \%$, considering a type I error of 0.05 . Regarding the measurement of NGAL, we determined that 18 patients were required in each group to detect a mean difference of $50 \mathrm{ng} / \mathrm{ml}$ (SD of $50 \mathrm{ng} / \mathrm{ml}$ ) to obtain a power of $80 \%$, considering a type I error of $0.05[15,16]$.

\section{Results}

A total of ninety-eight patients were randomized to receive EPO $(n=49)$ or normal saline $(n=49)$, and no patient was dropped out after group allocation (Figure 1). Patients' characteristics, including demographic data, EuroSCORE and preoperative renal function were not statistically different between the two groups (Table 1).

Operative characteristics, including the type of surgery performed, operation time, duration of $\mathrm{CPB}$ and $\mathrm{ACC}$ were similar between the two groups. Fluid balance, transfusion requirement, amount of ultrafiltration, re-infused volume from the cell savage device, vasopressor and inotropic requirement, and postoperative blood loss as measured by the volume of chest tube drainage were also similar between the two groups throughout the study period (Tables 2 and 3).

Overall, AKI occurred in 33 of 98 patients (34\%). The incidence of AKI was similar between the groups. Among the patients who developed AKI, a similar number of patients required renal replacement therapy during the hospital stay. There were no statistically significant differences in $\mathrm{sCr}$ levels, eGFR, creatinine clearance, cystatin $\mathrm{C}$ levels or serum NGAL levels between the two groups. The highest $\mathrm{sCr}$ level was observed at POD 1 in both groups (Table 4).

IL-6 and MPO were statistically significantly increased from their corresponding baseline values after the operation in both groups without any intergroup differences (Figure 2).

Perioperative hemodynamic variables, including mean arterial pressure, heart rate, central venous pressure, pulmonary capillary wedge pressure and cardiac index, were not different between the two groups (data not shown). Pre- and postoperative hematocrit levels were also similar between the two groups (Table 5).

The lengths of ICU and hospital stays were similar between the two groups. Remaining postoperative outcome variables were not different between the groups. One patient in the control group died during the hospital stay due to sepsis and acute respiratory distress syndrome (Table 6).

None of the patients developed adverse complications related to EPO administration including thromboembolic events throughout the study period.

\section{Discussion}

In this randomized controlled trial, we did not observe any beneficial influence of pre-emptive EPO administration on 


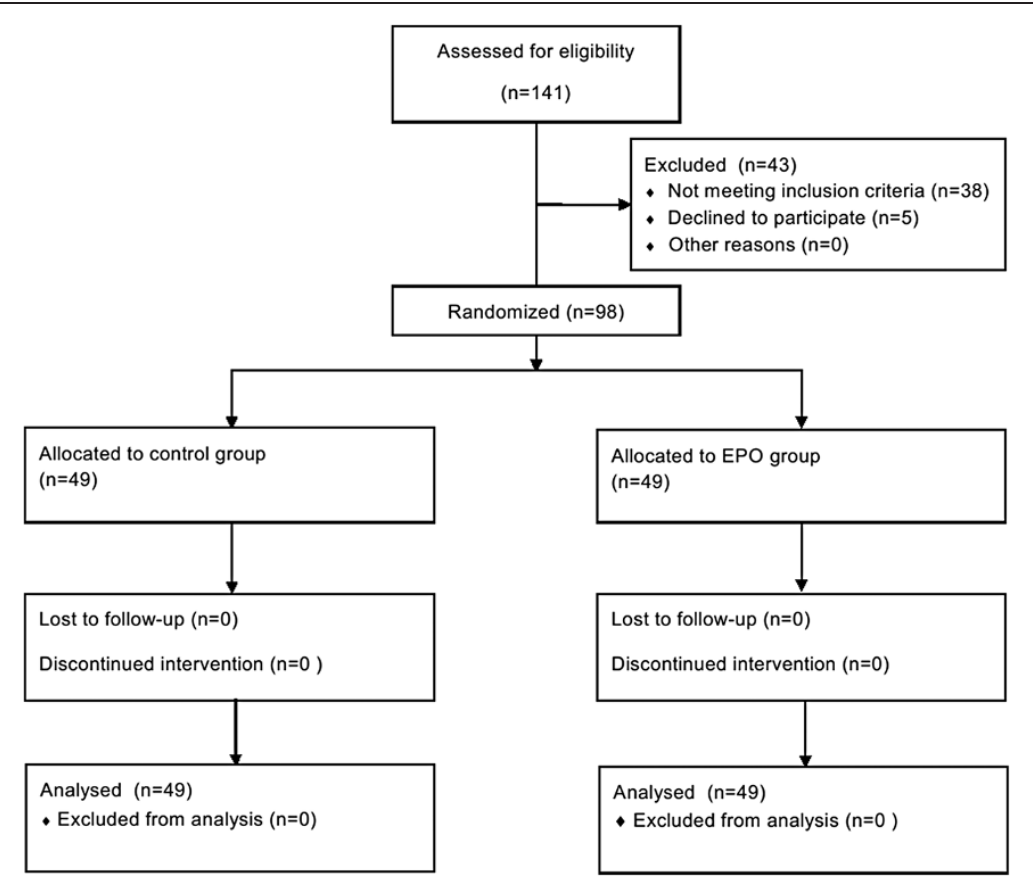

Figure 1 Diagram representing study cohort allocation.

the incidence of AKI and the degree of renal injury following complex valvular heart surgery in patients at risk of AKI. In addition, EPO did not attenuate the postoperative increase in IL-6 and MPO levels.

AKI occurs in up to $50 \%$ of patients after cardiac operations depending on the chosen AKI definition or type of operation $[1,17]$. AKI is associated with increased resource utilization and poor prognosis [2]. Known predisposing risk factors for AKI include advanced age, congestive heart failure, anemia, diabetes mellitus and decreased basal renal function [1]. Yet, the predominant risk factor for AKI continues to be the use of CPB [5,6]. In the pathogenesis of postoperative AKI, renal ischemia-reperfusion injury and systemic inflammatory response likely play pivotal roles [1]. Owing to its unique circulatory characteristics, the renal medulla is especially vulnerable to ischemic insults, as it normally receives blood with low oxygen tension [18]. Thus, the inevitable alterations caused by CPB, such as hemodilution, renal vasoconstriction, embolism and systemic inflammatory response, may contribute to the development of AKI [6]. Indeed, patients undergoing valvular heart surgery requiring prolonged $\mathrm{CPB}$ were shown to be more vulnerable to AKI [19]. Despite continuing clinical efforts to diminish renal injury through abrogation of the pathways related to ischemia-reperfusion injury and inflammation, no intervention has conclusively proven efficacy.

EPO, an endogenous hormone mainly produced in interstitial fibroblasts of the renal cortex and outer medulla, is responsible for stimulating red blood cell development in response to hypoxia. In addition, EPO has pleiotropic organ protection properties and elicits cytoprotective responses in numerous tissues [9]. In recent years, mounting experimental evidence regarding the cardio-, renal- and neuroprotective effects of EPO against ischemia-reperfusion or inflammation-induced injury has been documented [20]. EPO may attenuate apoptosis by reducing oxidative stress and proinflammatory activation [8]. Despite its sound experimental background $[8,9]$, only a few human studies have been performed regarding EPO's renal protective effects and these studies have produced conflicting results [11-13,21].

In a pilot study performed in low-risk patients undergoing coronary artery bypass graft surgery (CABG), $300 \mathrm{IU} / \mathrm{kg}$ of EPO significantly decreased the incidence of AKI and the degree of $\mathrm{sCr}$ elevation [11]. The authors observed similar results in a previous study addressing the role of $500 \mathrm{IU} / \mathrm{kg}$ of preemptive EPO treatment as a blood conservation strategy in patients undergoing valvular heart surgery [13]. Since the patients who received EPO treatment received significantly less transfusion blood, the renal protective effect of EPO could not be clarified in that previous study. Clinical evidence regarding the role of EPO in the prevention of AKI in cardiac surgical patients who are at increased risk of developing postoperative AKI is lacking.

Contrary to our expectations, a pre-emptive single bolus of $300 \mathrm{IU} / \mathrm{kg}$ of EPO neither reduced the incidence of AKI nor attenuated the increase in biomarkers of renal injury in this study. Although $\mathrm{sCr}$ is widely used for 
Table 1 Patients' demographics and preoperative clinical data

\begin{tabular}{|c|c|c|c|}
\hline Variable & $\begin{array}{c}\text { Control } \\
\text { (number }=49 \text { ) }\end{array}$ & $\begin{array}{c}\text { EPO } \\
\text { (number }=49 \text { ) }\end{array}$ & $P$ value \\
\hline Age (years) & $62 \pm 10$ & $63 \pm 10$ & 0.880 \\
\hline Female & $24(49)$ & $20(41)$ & 0.417 \\
\hline $\mathrm{BMI}\left(\mathrm{kg} / \mathrm{m}^{2}\right)$ & $24 \pm 4$ & $24 \pm 3$ & 0.528 \\
\hline \multicolumn{4}{|l|}{ Operation } \\
\hline$M V R+T A P$ & $6(12)$ & $8(16)$ & 0.564 \\
\hline Multi valve & $22(45)$ & $20(41)$ & 0.683 \\
\hline Valve + CABG & $8(16)$ & $7(14)$ & 0.779 \\
\hline Bentall & $13(27)$ & $14(29)$ & 0.821 \\
\hline Redo & $6(12)$ & $4(8)$ & 0.505 \\
\hline \multicolumn{4}{|l|}{ NYHA } \\
\hline$|-| \mid$ & $42(86)$ & $43(88)$ & 0.766 \\
\hline III-IV & $7(14)$ & $6(12)$ & \\
\hline EuroSCORE & $5.1 \pm 2.6$ & $5.7 \pm 2.5$ & 0.299 \\
\hline $\mathrm{DM}$ & $8(16)$ & $16(33)$ & 0.060 \\
\hline Hypertension & $24(49)$ & $27(55)$ & 0.544 \\
\hline Chronic kidney disease & $14(29)$ & $10(20)$ & 0.347 \\
\hline $\begin{array}{l}\text { Chronic obstructive lung } \\
\text { disease }\end{array}$ & $2(4)$ & $0(0)$ & 0.495 \\
\hline Ejection fraction (\%) & $60 \pm 13$ & $60 \pm 12$ & 0.798 \\
\hline Preoperative eGFR & $77 \pm 30$ & $83 \pm 28$ & 0.378 \\
\hline $\begin{array}{l}\text { Preoperative } \\
\mathrm{CrCl}<60 \mathrm{ml} / \mathrm{min}\end{array}$ & $21(43)$ & $17(35)$ & 0.407 \\
\hline \multicolumn{4}{|l|}{ Medication } \\
\hline$\beta$-blockers & $18(38)$ & $14(29)$ & 0.350 \\
\hline $\mathrm{CCB}$ & $17(35)$ & $13(27)$ & 0.344 \\
\hline ACEi & $17(35)$ & $12(25)$ & 0.240 \\
\hline ARB & $16(33)$ & $13(27)$ & 0.464 \\
\hline Diuretics & $28(58)$ & $28(57)$ & 0.906 \\
\hline Preoperative hematocrit (\%) & $38 \pm 6$ & $39 \pm 4$ & 0.375 \\
\hline
\end{tabular}

Values are mean \pm SD or number of patients (\%). ACEi, angiotensin-convertingenzyme inhibitors; ARB, angiotensin II receptor blockers; BMI, body mass index $C C B$, calcium channel blockers; $\mathrm{CrCl}$, creatinine clearance; DM, diabetes mellitus; eGFR, estimated glomerular filtration rate; EPO, erythropoietin; Multi valve, more than two valve replacement; MVR, mitral valve replacement; NYHA, New York Heart Association Functional Classification; TAP, tricuspid annuloplasty; Valve $+C A B G$, valvular replacement with coronary artery bypass grafting.

assessing renal function, it has inherent limitations as a late indicator of renal dysfunction and an inaccurate detector of mild renal impairment [22]. Cystatin C is more precise in detecting early and mild renal impairment than sCr [23]. Likewise, NGAL discriminates patients with subclinical AKI accompanied by normal $\mathrm{sCr}[24]$ and is an effective predictor of AKI after CABG [25]. As we could not observe any differences in the levels of cystatin $\mathrm{C}$ or NGAL between the two groups in the current trial, EPO
Table 2 Intraoperative parameters and fluid balance

\begin{tabular}{|c|c|c|c|}
\hline Variable & $\begin{array}{c}\text { Control } \\
\text { (number }=49 \text { ) }\end{array}$ & $\begin{array}{c}\text { EPO } \\
\text { (number }=49 \text { ) }\end{array}$ & $P$ value \\
\hline Operation time (min) & $253 \pm 68$ & $243 \pm 63$ & 0.480 \\
\hline CPB time (min) & $129 \pm 42$ & $128 \pm 39$ & 0.870 \\
\hline ACC time (min) & $96 \pm 38$ & $96 \pm 30$ & 0.894 \\
\hline $\begin{array}{l}\text { Norepinephrine } \\
\text { infused }(\mu \mathrm{g})\end{array}$ & 70 (40 to 117$)$ & 68 (36 to 101) & 0.350 \\
\hline $\begin{array}{l}\text { Amount of } \\
\text { ultrafiltration (ml) }\end{array}$ & $1,000$ (563 to 1,575$)$ & 1,000 (450 to 2,000 ) & 0.936 \\
\hline \multicolumn{4}{|l|}{$\begin{array}{l}\text { Fluid balance during } \\
\text { operation }\end{array}$} \\
\hline crystalloid (ml) & $1,570 \pm 531$ & $1,579 \pm 487$ & 0.934 \\
\hline colloid (ml) & 500 (350 to 600) & 450 (300 to 575$)$ & 0.398 \\
\hline urine output (ml) & $1,022 \pm 493$ & $1,004 \pm 505$ & 0.863 \\
\hline $\begin{array}{l}\text { Amount of pRBC } \\
\text { transfusion }(\mathrm{ml})\end{array}$ & $219 \pm 384$ & $122 \pm 162$ & 0.107 \\
\hline $\begin{array}{l}\text { Amount of cell } \\
\text { salvaged blood (ml) }\end{array}$ & 550 (490 to 765 ) & 500 (480 to 748$)$ & 0.268 \\
\hline $\begin{array}{l}\text { Patients transfused } \\
\text { with pRBCs (number) }\end{array}$ & $20(41)$ & $21(43)$ & 0.838 \\
\hline
\end{tabular}

Values are mean \pm SD or median (25th to 75th). ACC, aorta cross clamp; CPB, cardiopulmonary bypass; EPO, erythropoietin; $\mathrm{PRBCS}$, packed red blood cells.

does not seem to provide any renal protection to the patient population in this study. Furthermore, the given dose of EPO did not exert any influence on the IL- 6 and MPO levels in this study. IL-6 is a reliable marker of inflammatory cascade activation and is an indicator of poor outcomes [26], whereas MPO represents polymorphonuclear leukocyte accumulation [27]. Leukocyte infiltration is one of the key initiating processes of renal ischemia-reperfusion injury [28]. Both IL-6 and MPO were significantly attenuated with EPO in an experimental ischemic myocardial model $[10,27]$ but not in this study.

There are several plausible explanations for the lack of benefit from EPO treatment. First, as our results indicate, the percentage of patients requiring renal replacement therapy was higher in the current trial compared with other studies [11,12]. Thus, the employment of a single preventive strategy to mitigate the development of AKI may not be enough to inhibit the numerous interconnections of signaling pathways that lead to renal injury. Multimodal strategies acting on various mechanisms may be required to mitigate the incidence of AKI in this highrisk group of patients. Second, the optimal dosage of EPO treatment to induce tissue protection has not been established clinically. In the present study, the dose of EPO (300 IU/kg) was decided based on a previous clinical study demonstrating the renal protective effects of EPO in lowrisk patients undergoing CABG [11]. Although most of the patients in that study underwent off-pump CABG, $\mathrm{CPB}$ was reported to have no apparent influence on the pharmacokinetics of a single bolus of EPO [29]. The 
Table 3 Postoperative care at ICU

\begin{tabular}{|c|c|c|c|}
\hline Variable & $\begin{array}{c}\text { Control } \\
\text { (number = 49) }\end{array}$ & $\begin{array}{c}\text { EPO } \\
\text { (number }=49)\end{array}$ & $P$ value \\
\hline \multicolumn{4}{|l|}{ Crystalloid infused (ml) } \\
\hline at ICU POD 0 & $2795 \pm 994$ & $3045 \pm 1054$ & 0.231 \\
\hline at ICU POD 1 & $2380 \pm 695$ & $2261 \pm 861$ & 0.452 \\
\hline \multicolumn{4}{|l|}{ Colloid infused (ml) } \\
\hline at ICU POD 0 & 280 (100 to 500) & 150 (0 to 500$)$ & 0.139 \\
\hline at ICU POD 1 & $0(0$ to 0$)$ & $0(0$ to 0$)$ & 0.317 \\
\hline \multicolumn{4}{|l|}{ Urine output (ml) } \\
\hline at ICU POD 0 & $2,180 \pm 701$ & $2,389 \pm 832$ & 0.182 \\
\hline at ICU POD 1 & $2,520 \pm 722$ & $2,628 \pm 537$ & 0.401 \\
\hline \multicolumn{4}{|l|}{ pRBCs transfused (ml) } \\
\hline at ICU POD 0 & $223 \pm 344$ & $222 \pm 601$ & 0.987 \\
\hline at ICU POD 1 & $63 \pm 182$ & $44 \pm 136$ & 0.555 \\
\hline \multicolumn{4}{|l|}{ Chest tube drainage $(\mathrm{ml})$} \\
\hline at ICU POD 0 & 390 (195 to 580) & 330 (195 to 595) & 0.394 \\
\hline at ICU POD 1 & 240 (165 to 375$)$ & 270 (180 to 440 ) & 0.153 \\
\hline $\begin{array}{l}\text { Patients transfused } \\
\text { with pRBCs (number) } \\
\text { at POD } 0 \text { and } 1\end{array}$ & $16(33)$ & $23(47)$ & 0.149 \\
\hline $\begin{array}{l}\text { Patients treated with } \\
\text { vasopressors (number) } \\
\text { at POD } 0 \text { and } 1\end{array}$ & $18(37)$ & $12(25)$ & 0.188 \\
\hline $\begin{array}{l}\text { Patients treated with } \\
\text { inotropics (number) } \\
\text { at POD } 0 \text { and } 1\end{array}$ & $21(43)$ & $17(35)$ & 0.407 \\
\hline
\end{tabular}

Values are mean \pm SD or median (25th to 75 th). ACC, aorta cross clamp; CPB, cardiopulmonary bypass; EPO, erythropoietin; POD, postoperative day; PRBCs, packed red blood cells.

inconsistent results of the current study from that previous study might be associated with the different degree of the risk of the enrolled patients for postoperative AKI and the degree of inflammatory and oxidative stress between both studies.

Generally, higher doses of EPO are considered necessary for tissue protection than for erythropoiesis because of the lower affinity of the EPO heteroreceptor [9,30]. On the other hand, EPO's organ protective effects at lower dosages $(<500 \mathrm{IU} / \mathrm{kg})$ have also been observed [31]. Similarly, some studies using higher doses of EPO have failed to show a beneficial effect [32]. Indeed, no difference in changes of urinary NGAL has been reported in a study that randomized post cardiac surgical patients up to 40,000 IU EPO, which is in accordance with the results of the current study [12]. Although used in a different clinical setting, doses up to 60,000 IU used in patients with myocardial infarction within four-hour reperfusion also could not provide any beneficial influence in terms of infarct size reduction [33]. Of note, the incidence of adverse cardiovascular events including death was significantly higher in patients who received
Table 4 Variables associated with renal outcomes

\begin{tabular}{lccc}
\hline Variable & $\begin{array}{c}\text { Control } \\
\text { (number }=49)\end{array}$ & $\begin{array}{c}\text { EPO } \\
\text { (number }=49)\end{array}$ & $\begin{array}{c}\boldsymbol{P} \\
\text { value }\end{array}$ \\
\hline Postoperative AKI & $16(0.33$, & $17(0.35$, & 0.831 \\
& 0.26 to 0.39$)$ & 0.28 to 0.42$)$ & \\
Stage 1 & $12(0.25$, & $12(0.25$, & 1.000 \\
& 0.18 to 0.31$)$ & 0.18 to 0.31$)$ &
\end{tabular}

Stage 2

(0

Stage 3

Postoperative

dialysis

Serum creatinine

$(\mathrm{mg} / \mathrm{dl})$

Baseline
ICU arrival
POD 1
POD 2
POD 3
POD 5
Cystatin C (mg/L)
Baseline
ICU arrival
POD 1
POD 2
POD 3

$4(0.08$
0.04 to 0.12$)$
$4(0.08$
0.04 to 0.12$)$

0

1.000

$5(0.10$

0.06 to 0.15$)$

0.727

$(0.10,0.06$ to

0.727

$0.15)$

$0.99 \pm 0.27$

$0.92 \pm 0.28$

$0.090^{\mathrm{b}}$

eGFR

$\left(\mathrm{mL} / \mathrm{min} / 1.73 \mathrm{~m}^{2}\right)$

\begin{tabular}{lccc} 
Baseline & $77 \pm 30$ & $83 \pm 28$ & 0.381 \\
ICU arrival & $89 \pm 36^{\mathrm{a}}$ & $94 \pm 46^{\mathrm{a}}$ & 0.556 \\
POD 1 & $80 \pm 46$ & $79 \pm 43$ & 0.941 \\
POD 2 & $72 \pm 36$ & $71 \pm 30^{\mathrm{a}}$ & 0.985 \\
POD 3 & $79 \pm 35$ & $76 \pm 30$ & 0.659 \\
POD 5 & $88 \pm 32^{\mathrm{a}}$ & $89 \pm 30^{\mathrm{a}}$ & 0.863 \\
og NGAL & & & $0.891^{\mathrm{b}}$ \\
Baseline & $1.53 \pm 0.28$ & $1.56 \pm 0.26$ & 0.780 \\
1 hourr & $2.21 \pm 0.26^{\mathrm{a}}$ & $2.16 \pm 0.28^{\mathrm{a}}$ & 0.591 \\
after ACC off & & & \\
6 hourr after & $2.24 \pm 0.33^{\mathrm{a}}$ & $2.17 \pm 0.33^{\mathrm{a}}$ & 0.550 \\
ACC off & & & \\
24 hourr after & $2.17 \pm 0.37^{\mathrm{a}}$ & $2.14 \pm 0.36^{\mathrm{a}}$ & 0.846 \\
operation & & & \\
\hline
\end{tabular}

Values are number of patients (probability, $95 \%$ confidence interval) or mean \pm SD. ${ }^{\mathrm{a}} P<0.05$, compared with baseline; ${ }^{\mathrm{b}} P_{\text {group }}$ t time $=P$-value of the group and time interaction obtained by the linear mixed model. ACC, aortic cross clamp; AKI, acute kidney injury; eGFR, estimated glomerular filtration rate; EPO, erythropoietin; Log NGAL, logarithm of neutrophil gelatinase-associated lipocalin; POD, postoperative days.

EPO in that study, raising alarm against the use of higher doses of EPO.

Despite the organ protective effects observed in animal experiments, a recently increasing amount of negative 


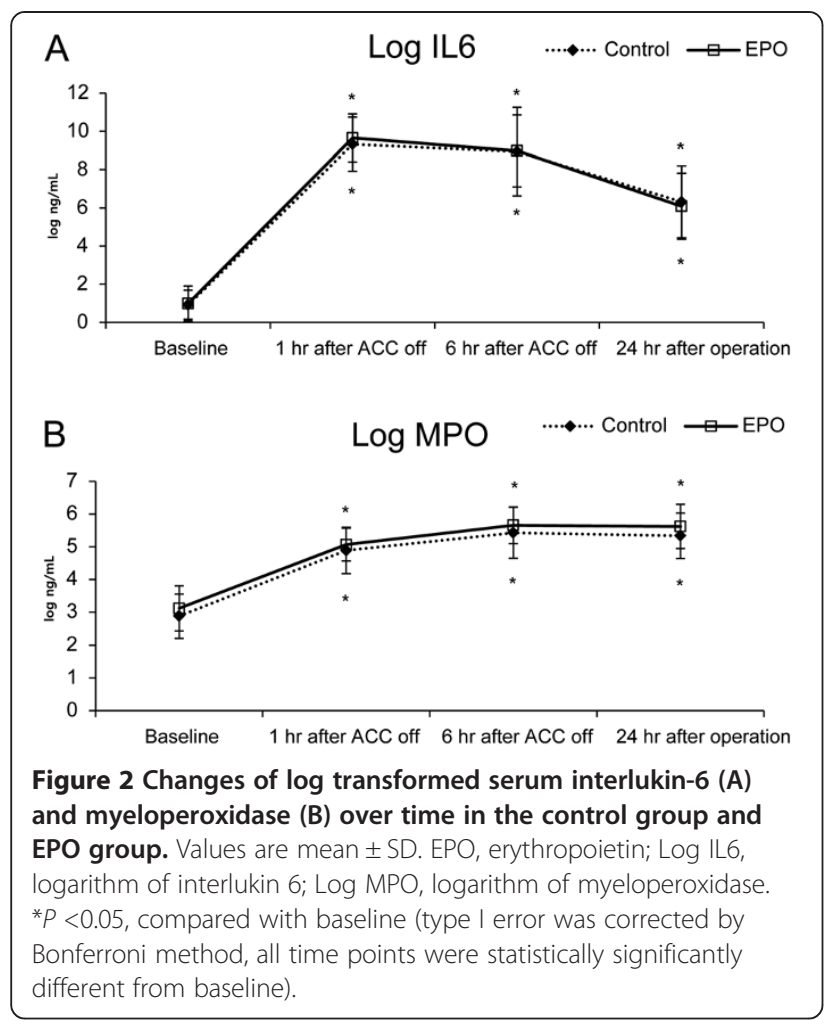

evidence regarding the tissue protective effects of EPO has been documented in clinical trials. In terms of EPO's anti-inflammatory effects, EPO did not suppress the systemic inflammatory response [12,26] and, instead, augmented the cytokine response to acute inflammation [34]. In accordance with those reports, no convincing trend in any of the serum levels of MPO and IL-6 was observed in the EPO group in the current trial. Of interest, one experiment in a porcine model suggested that EPO may protect against injuries related to direct ischemia but not injuries related to inflammation [32]. Considering that most experimental studies reporting the renal protective effects of EPO used a direct renal ischemia-reperfusion model, different mechanisms and degrees of renal injury in procedures using $\mathrm{CPB}$ without overt mechanical renal ischemia could also be responsible

Table 5 Changes of hematocrit during perioperative period

\begin{tabular}{lllllll}
\hline Group & Preoperative & POD 0 & POD 1 & POD 2 & POD 3 & POD 5 \\
\hline $\begin{array}{l}\text { Control } \\
(n=49)\end{array}$ & $38 \pm 6$ & $31 \pm 4$ & $29 \pm 3$ & $28 \pm 3$ & $27 \pm 3$ & $27 \pm 3$ \\
$\begin{array}{l}E P O \\
(n=49)\end{array}$ & $39 \pm 4$ & $31 \pm 5$ & $29 \pm 4$ & $28 \pm 4$ & $28 \pm 4$ & $29 \pm 3$ \\
$P$ value & 0.375 & 0.756 & 0.227 & 0.369 & 0.192 & 0.131 \\
\hline
\end{tabular}

Values are mean \pm SD. EPO, erythropoietin; POD, postoperative days.
Table 6 Postoperative outcome

\begin{tabular}{|c|c|c|c|}
\hline Variable & $\begin{array}{c}\text { Control } \\
\text { (number }=49 \text { ) }\end{array}$ & $\begin{array}{c}\text { EPO } \\
\text { (number }=49 \text { ) }\end{array}$ & $P$ value \\
\hline Duration of ICU stay (days) & $4.0 \pm 5.1$ & $3.5 \pm 2.8$ & 0.593 \\
\hline $\begin{array}{l}\text { Duration of hospital stay } \\
\text { (days) }\end{array}$ & 14 (12 to 18$)$ & 15 (12 to 18$)$ & 0.695 \\
\hline Ventilatory care $>48$ hours & $3(6)$ & $2(4)$ & 0.646 \\
\hline Postoperative inotrope use & $17(35)$ & $13(27)$ & 0.381 \\
\hline Re-intubation & $0(0)$ & $2(4)$ & 0.495 \\
\hline Re-operation & $2(4)$ & $3(6)$ & 1.000 \\
\hline $\begin{array}{l}\text { Postoperative atrial } \\
\text { fibrillation }\end{array}$ & $14(29)$ & $9(18)$ & 0.233 \\
\hline Stroke & $1(2)$ & $2(4)$ & 1.000 \\
\hline Death & $1(2)$ & $0(0)$ & 1.000 \\
\hline
\end{tabular}

Values are mean \pm SD or median (25th to 75 th) or number of patients (\%). EPO, erythropoietin.

for the different results observed in clinical trials. As yet, the promising organ protective effects of EPO in experimental studies could not be consistently reproduced in clinical trials for numerous possible reasons that are beyond the scope of this study.

There are several limitations of this study. First, the sample size may not have been sufficient, as the actual incidence of AKI was lower than expected. Still, we did not observe any trend indicating a potential benefit of $E P O$, even with the sensitive biomarkers of renal injury known to detect subtle forms of renal dysfunction. Therefore, it seems reasonable to conclude that the given dose of EPO does not offer renal protection in the studied population. Second, more patients had DM in the EPO group, although these results were not statistically significant. DM was reported to mitigate the tissue protective effect of EPO, as well as various preconditioning strategies in animal studies [35-39]. There were no differences in mean blood glucose levels, renal biomarkers and the incidence of AKI between the groups even in patients without DM (data not shown). Moreover, DM as covariate in the linear mixed model for $\mathrm{s} C r$ to test whether it changes by the group and time interaction did not show any intergroup difference $(P=0.935)$; thus, the confounding effect of DM should be negligible. Third, the use of Voluven ${ }^{\circ}$ might have confounded the results. Increasing evidence warns about the potentially harmful influence of hydroxyethyl starch solutions on AKI in critically ill patients $[16,40]$. However, the use of a limited amount of low molecular weight hydroxyethyl starch (less than $500 \mathrm{ml}$ of Voluven per day) does not seem to exert any influence on AKI as evidenced by the lack of association between the amount of Voluven ${ }^{\circ}$ and changes in $\mathrm{sCr}$ in the current study (data not shown). Also, as both groups received a similar amount of Voluven during the study period, its influence should be the same, if any should exist. 


\section{Conclusions}

Intravenous administration of a pre-emptive single bolus of $300 \mathrm{IU} / \mathrm{kg}$ of EPO did not decrease the incidence of AKI. It also failed to attenuate the increase in the serum levels of biomarkers of renal injury and Il-6 and MPO activation. A single preventive strategy, such as EPO, may not suffice in patients at increased risk of developing AKI after undergoing complex valvular heart surgery.

\section{Key massages}

- Intravenous administration of a pre-emptive single bolus of $300 \mathrm{IU} / \mathrm{kg}$ of EPO did not decrease the incidence of acute kidney injury.

- It also failed to attenuate the increase in the serum levels of biomarkers of renal injury, such as $\mathrm{sCr}$, cystatin $C$ and NGAL.

- In terms of the anti-inflammatory effects of EPO, administration of a preemptive single bolus of $300 \mathrm{IU} / \mathrm{kg}$ of erythropoietin did not decrease IL-6 and MPO.

\begin{abstract}
Abbreviations
ACC: Aortic cross clamp; ACEi: Angiotensin-converting-enzyme inhibitors: AKI: Acute kidney injury; AKIN: Acute kidney injury network; ARB: Angiotensin II receptor blockers; ARF: Acute renal failure; AVR: Aortic valve replacement; BMI: Body mass index; CABG: Coronary artery bypass graft surgery; CCB: calcium channel blockers; CPB: Cardiopulmonary bypass;

CrCl: Creatinine clearance; DM: Diabetes mellitus; eGFR: Estimated glomerular filtration rate; EPO: Erythropoietin; IL-6: Interleukin 6; MPO: Myeloperoxidase; MVR: Mitral valve replacement; NGAL: Neutrophil gelatinase-associated lipocalin; NYHA: New York heart association functional classification;

POD: Postoperative day; pRBCs: Packed red blood cells; sCr: Serum creatinine.
\end{abstract}

\section{Competing interests}

The authors declare that they have no competing interests.

\section{Authors' contributions}

JHK and YLK conceived the study design, collected, analyzed and interpreted the data, performed the statistical analysis and wrote the manuscript. JKS contributed substantially to interpreting the data and critically revised the manuscript for important intellectual content. JWS and YS contributed substantially to collecting and interpreting the data. HBK contributed substantially to collecting the data. All authors read and approved the final manuscript.

\section{Acknowledgements}

This study was approved by the Severance hospital Institutional Review Board (No. 4-2011-0355) and Korea Food \& Drug Administration (No. 11942). This study was supported by a CMB-Yuhan research grant of Yonsei University College of Medicine for 2011 (6-2011-0063).

\section{Author details}

${ }^{1}$ Department of Anesthesiology and Pain Medicine, National Health Insurance Service Ilsan Hospital, Gyeonggi-do, South Korea. ${ }^{2}$ Department of Anesthesiology and Pain Medicine, Anesthesia and Pain Research Institute, Yonsei University Health System, Seoul, South Korea. ${ }^{3}$ Biomedical Science Institute, Department of Anesthesiology and Pain Medicine, Anesthesia and Pain Research Institute, Yonsei University Health System, 250 Seongsanno, Sedaemun-gu, Seoul 120-752, South Korea.

Received: 4 August 2013 Accepted: 7 October 2013

Published: 24 October 2013

\section{References}

1. Mariscalco G, Lorusso R, Dominici C, Renzulli A, Sala A: Acute kidney injury: a relevant complication after cardiac surgery. Ann Thorac Surg 2011 , 92:1539-1547.

2. Thakar CV, Yared JP, Worley S, Cotman K, Paganini EP: Renal dysfunction and serious infections after open-heart surgery. Kidney Int 2003, 64:239-246.

3. Lassnigg A, Schmidlin D, Mouhieddine M, Bachmann LM, Druml W, Bauer P, Hiesmayr M: Minimal changes of serum creatinine predict prognosis in patients after cardiothoracic surgery: a prospective cohort study. J Am Soc Nephrol 2004, 15:1597-1605.

4. Conlon PJ, Stafford-Smith M, White WD, Newman MF, King S, Winn MP, Landolfo K: Acute renal failure following cardiac surgery. Nephrol Dial Transplant 1999, 14:1158-1162.

5. Rosner MH, Okusa MD: Acute kidney injury associated with cardiac surgery. Clin J Am Soc Nephrol 2006, 1:19-32.

6. Kumar $A B$, Suneja M: Cardiopulmonary bypass-associated acute kidney injury. Anesthesiology 2011, 114:964-970.

7. Tuttle KR, Worrall NK, Dahlstrom LR, Nandagopal R, Kausz AT, Davis CL: Predictors of ARF after cardiac surgical procedures. Am J Kidney Dis 2003, 41:76-83.

8. Katavetin P, Tungsanga K, Eiam-Ong S, Nangaku M: Antioxidative effects of erythropoietin. Kidney Int Supp/ 2007, 107:S10-S15.

9. Moore E, Bellomo R: Erythropoietin (EPO) in acute kidney injury. Ann Intensive Care 2011, 1:3.

10. Shen $Y$, Wang $Y$, Li D, Wang C, Xu B, Dong G, Huang H, Jing H: Recombinant human erythropoietin pretreatment attenuates heart ischemia-reperfusion injury in rats by suppressing the systemic inflammatory response. Transplant Proc 2010, 42:1595-1597.

11. Song YR, Lee T, You SJ, Chin HJ, Chae DW, Lim C, Park KH, Han S, Kim JH, $\mathrm{Na} \mathrm{KY}$ : Prevention of acute kidney injury by erythropoietin in patients undergoing coronary artery bypass grafting: a pilot study. Am J Nephrol 2009, 30:253-260.

12. de Seigneux S, Ponte B, Weiss L, Pugin J, Romand JA, Martin PY, Saudan P: Epoetin administrated after cardiac surgery: effects on renal function and inflammation in a randomized controlled study. BMC Nephrol 2012, 13:132.

13. Yoo YC, Shim JK, Kim JC, Jo YY, Lee JH, Kwak YL: Effect of single recombinant human erythropoietin injection on transfusion requirements in preoperatively anemic patients undergoing valvular heart surgery. Anesthesiology 2011, 115:929-937.

14. Mehta RL, Kellum JA, Shah SV, Molitoris BA, Ronco C, Warnock DG, Levin A: Acute Kidney Injury Network: report of an initiative to improve outcomes in acute kidney injury. Crit Care 2007, 11:R31.

15. Prabhu A, Sujatha DI, Ninan B, Vijayalakshmi MA: Neutrophil gelatinase associated lipocalin as a biomarker for acute kidney injury in patients undergoing coronary artery bypass grafting with cardiopulmonary bypass. Ann Vasc Surg 2010, 24:525-531.

16. Tuladhar SM, Puntmann VO, Soni M, Punjabi PP, Bogle RG: Rapid detection of acute kidney injury by plasma and urinary neutrophil gelatinase-associated lipocalin after cardiopulmonary bypass. J Cardiovasc Pharm 2009, 53:261-266

17. Arnaoutakis GJ, Bihorac A, Martin TD, Hess PJ Jr, Klodell CT, Ejaz AA, Garvan C, Tribble CG, Beaver TM: RIFLE criteria for acute kidney injury in aortic arch surgery. J Thorac Cardiov Surg 2007, 134:1554-1560. discussion 1560-1551.

18. Janssen WM, Beekhuis $H$, de Bruin $R$, de Jong PE, de Zeeuw D: Noninvasive measurement of intrarenal blood flow distribution: kinetic model of renal 123I-hippuran handling. Am J Physiol 1995, 269:F571-F580.

19. Mehta RH, Grab JD, O'Brien SM, Bridges CR, Gammie JS, Haan CK, Ferguson TB, Peterson ED, Society of Thoracic Surgeons National Cardiac Surgery Database Investigators: Bedside tool for predicting the risk of postoperative dialysis in patients undergoing cardiac surgery. Circulation 2006, 114:2208-2216. quiz 2208

20. Joyeux-Faure M: Cellular protection by erythropoietin: new therapeutic implications? J Pharmacol Exp Ther 2007, 323:759-762.

21. Oh SW, Chin HJ, Chae DW, Na KY: Erythropoietin improves long-term outcomes in patients with acute kidney injury after coronary artery bypass grafting. J Korean Med Sci 2012, 27:506-511.

22. Shemesh $\mathrm{O}$, Golbetz H, Kriss JP, Myers BD: Limitations of creatinine as a filtration marker in glomerulopathic patients. Kidney Int 1985, 28:830-838. 
23. Roos JF, Doust J, Tett SE, Kirkpatrick CM: Diagnostic accuracy of cystatin C compared to serum creatinine for the estimation of renal dysfunction in adults and children-a meta-analysis. Clin Biochem 2007, 40:383-391.

24. Haase M, Devarajan P, Haase-Fielitz A, Bellomo R, Cruz DN, Wagener G, Krawczeski CD, Koyner JL, Murray P, Zappitelli M, Goldstein SL, Makris K, Ronco C, Martensson J, Martling CR, Venge P, Siew E, Ware LB, Ikizler TA, Mertens PR: The outcome of neutrophil gelatinase-associated lipocalin-positive subclinical acute kidney injury: a multicenter pooled analysis of prospective studies. J Am Coll Cardiol 2011, 57:1752-1761.

25. Loef BG, Epema AH, Smilde TD, Henning RH, Ebels T, Navis G, Stegeman CA: Immediate postoperative renal function deterioration in cardiac surgical patients predicts in-hospital mortality and long-term survival. J Am SOC Nephrol 2005, 16:195-200.

26. Poulsen TD, Andersen LW, Steinbruchel D, Gotze JP, Jorgensen OS, Olsen NV: Two large preoperative doses of erythropoietin do not reduce the systemic inflammatory response to cardiac surgery. J Cardiothorac Vasc Anesth 2009, 23:316-323.

27. Patel NS, Sharples EJ, Cuzzocrea S, Chatterjee PK, Britti D, Yaqoob MM, Thiemermann C: Pretreatment with EPO reduces the injury and dysfunction caused by ischemia/reperfusion in the mouse kidney in vivo. Kidney Int 2004, 66:983-989.

28. Bonventre JV, Weinberg JM: Recent advances in the pathophysiology of ischemic acute renal failure. J Am Soc Nephrol 2003, 14:2199-2210.

29. McCluskey SA, Cheung WK, Katznelson R, Poonawala H, Fedorko L, Djaiani G, Mehta B, Karkouti $K$ : The pharmacokinetic profile of recombinant human erythropoietin is unchanged in patients undergoing cardiac surgery. Eur J Clin Pharmacol 2009, 65:273-279.

30. Brines $M$, Cerami A: Erythropoietin-mediated tissue protection: reducing collateral damage from the primary injury response. J Intern Med 2008, 264:405-432.

31. Simon F, Scheuerle A, Calzia E, Bassi G, Oter S, Duy CN, Kick J, Bruckner UB, Radermacher P, Schelzig H: Erythropoietin during porcine aortic balloon occlusion-induced ischemia/reperfusion injury. Crit Care Med 2008, 36:2143-2150.

32. Solling C, Christensen AT, Nygaard U, Krag S, Frokiaer J, Wogensen L, Krog J, Tonnesen EK: Erythropoietin does not attenuate renal dysfunction or inflammation in a porcine model of endotoxemia. Acta Anaesthiol Scand 2011, 55:411-421.

33. Najjar SS, Rao SV, Melloni C, Raman SV, Povsic TJ, Melton L, Barsness GW, Prather K, Heitner JF, Kilaru R, Gruberg L, Hasselblad V, Greenbaum AB, Patel M, Kim RJ, Talan M, Ferrucci L, Longo DL, Lakatta EG, Harrington RA: REVEAL Investigators: Intravenous erythropoietin in patients with ST-segment elevation myocardial infarction: REVEAL: a randomized controlled trial. JAMA 2011, 305:1863-1872.

34. Hojman P, Taudorf S, Lundby C, Pedersen BK: Erythropoietin augments the cytokine response to acute endotoxin-induced inflammation in humans. Cytokine 2009, 45:154-157.

35. Ghaboura N, Tamareille S, Ducluzeau PH, Grimaud L, Loufrani L, Croue A Tourmen Y, Henrion D, Furber A, Prunier F: Diabetes mellitus abrogates erythropoietin-induced cardioprotection against ischemic-reperfusion injury by alteration of the RISK/GSK-3beta signaling. Basic Res Cardiol 2011, 106:147-162.

36. Gross ER, Hsu AK, Gross GJ: Diabetes abolishes morphine-induced cardioprotection via multiple pathways upstream of glycogen synthase kinase-3beta. Diabetes 2007, 56:127-136.

37. Tanaka K, Kehl F, Gu W, Krolikowski JG, Pagel PS, Warltier DC, Kersten JR: Isoflurane-induced preconditioning is attenuated by diabetes. Am J Physiol Heart Circ Physiol 2002, 282:H2018-H2023.

38. Kim HS, Cho JE, Hwang KC, Shim YH, Lee JH, Kwak YL: Diabetes mellitus mitigates cardioprotective effects of remifentanil preconditioning in ischemia-reperfused rat heart in association with anti-apoptotic pathways of survival. Eur J Pharmacol 2010, 628:132-139.
39. Jensen RV, Stottrup NB, Kristiansen SB, Botker HE: Release of a humoral circulating cardioprotective factor by remote ischemic preconditioning is dependent on preserved neural pathways in diabetic patients. Basic Res Cardiol 2012, 107:285.

40. Myburgh JA, Finfer S, Bellomo R, Billot L, Cass A, Gattas D, Glass P, Lipman J, Liu B, McArthur C, McGuinness S, Rajbhandari D, Taylor CB, Webb SA, CHEST Investigators, Australian and New Zealand Intensive Care Society Clinical Trials Group: Hydroxyethyl starch or saline for fluid resuscitation in intensive care. New Engl J Med 2012, 367:1901-1911.

\section{doi:10.1186/cc13081}

Cite this article as: Kim et al: Effect of erythropoietin on the incidence of acute kidney injury following complex valvular heart surgery: a double blind, randomized clinical trial of efficacy and safety. Critical Care 2013 17:R254.

\section{Submit your next manuscript to BioMed Central and take full advantage of:}

- Convenient online submission

- Thorough peer review

- No space constraints or color figure charges

- Immediate publication on acceptance

- Inclusion in PubMed, CAS, Scopus and Google Scholar

- Research which is freely available for redistribution

Submit your manuscript at www.biomedcentral.com/submit
C Biomed Central 